\title{
\begin{tabular}{l|l} 
Mitraries & DSpace@MIT
\end{tabular}
}

\author{
MIT Open Access Articles
}

\section{Development of a Compensation Chamber for Use in a Multiple Condenser Loop Heat Pipe}

The MIT Faculty has made this article openly available. Please share how this access benefits you. Your story matters.

Citation: Roche, Nicholas A., Martin Cleary, Teresa B. Peters, Evelyn N. Wang, and John G. Brisson. "Development of a Compensation Chamber for Use in a Multiple Condenser Loop Heat Pipe." Volume 2: Heat Transfer Enhancement for Practical Applications; Heat and Mass Transfer in Fire and Combustion; Heat Transfer in Multiphase Systems; Heat and Mass Transfer in Biotechnology (July 14, 2013).

As Published: http://dx.doi.org/10.1115/HT2013-17581

Publisher: ASME International

Persistent URL: http://hdl.handle.net/1721.1/119180

Version: Final published version: final published article, as it appeared in a journal, conference proceedings, or other formally published context

Terms of Use: Article is made available in accordance with the publisher's policy and may be subject to US copyright law. Please refer to the publisher's site for terms of use. 


\title{
DEVELOPMENT OF A COMPENSATION CHAMBER FOR USE IN A MULTIPLE CONDENSER LOOP HEAT PIPE
}

\author{
Nicholas A. Roche, Martin Cleary, Teresa B. Peters, Evelyn N. Wang, and John G. Brisson \\ Department of Mechanical Engineering \\ Massachusetts Institute of Technology \\ Cambridge, MA 02139 \\ Email: nroche@mit.edu
}

\begin{abstract}
We report the design and analysis of a novel compensation chamber for use in PHUMP, a multiple condenser loop heat pipe (LHP) capable of dissipating $1000 \mathrm{~W}$. The LHP is designed for integration into a high performance air-cooled heat sink to address thermal management challenges in advanced electronic systems. The compensation chamber is integrated into the evaporator of the device and provides a region for volumetric expansion of the working fluid over a range of operating temperatures. Additionally, the compensation chamber serves to set the liquid side pressure of the device, preventing both flooding of the condensers and dry out of the evaporator. The compensation chamber design was achieved through a combination of computational simulation using COMSOL Multiphysics and models developed based on experimental work of previous designs. The compensation chamber was fabricated as part of the evaporator using Copper and Monel sintered wicks with various particle sizes to achieve the desired operating characteristics. Currently, the compensation chamber is being incorporated into a multiple condenser LHP for a high performance air-cooled heat sink.
\end{abstract}

\section{INTRODUCTION}

As the performance of electronic devices has increased, so too has the need for efficient and reliable thermal management solutions. Despite advances in the field, thermal management remains a critical bottleneck for high-power systems such as phased array radar and digital electronics. Here, a compact aircooled loop heat pipe known as PHUMP is presented as a potential solution to these issues.

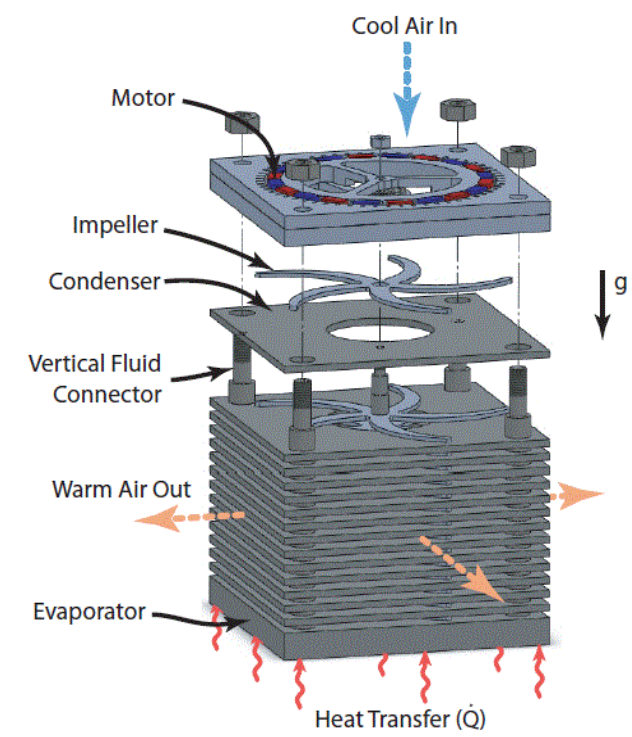

Figure 1: Schematic of PHUMP. Heat is conducted into the evaporator where it causes phase change of the working fluid; condensation occurs in the numerous planar condensers, which are cooled by impellers interdigitated between each layer.

The novel design of PHUMP utilizes a loop heat pipe with interdigitated impellers to efficiently dissipate heat. A schematic of the overall device is shown above in Fig. 1. Heat is input into the evaporator at the base of the device, where it causes a phase change of the working fluid from liquid into vapor. This vapor then travels through vertical transport lines into the device's condensers, where it is cooled and condenses back into its liquid state. The liquid then travels through separate transport lines into the evaporator, completing the cycle. The multiple condensers of PHUMP are air-cooled by 
impellers driven by a low profile electric motor. Air enters the device through an axial inlet at the top and is exhausted radially out the sides after passing over the condensers. Water is used as a working fluid for its high latent heat of evaporation and surface tension.

PHUMP is designed to dissipate $1000 \mathrm{~W}$ of heat at a temperature difference of $50^{\circ} \mathrm{C}$ while using less than $33 \mathrm{~W}$ of electric power to drive the impellers. This results in a thermal resistance of $0.05{ }^{\circ} \mathrm{C} / \mathrm{W}$ and a coefficient of performance (COP, defined as the ratio of heat dissipated to electrical work input) of 33. To aid in application, the overall dimensions of the device are $10 \mathrm{~cm} \times 10 \mathrm{~cm} \times 10 \mathrm{~cm}$. The combination of a compact form factor with advanced performance yields a device that represents a significant advancement of current state of the art thermal management solutions. The device's unique properties present a number of challenges to both its manufacture and design, the latter of which is discussed here.

A detailed cross-sectional view of the evaporator and a condenser within PHUMP is shown in Fig. 2. Sintered wicks are employed in the evaporator and condensers of the device to drive flow of the working fluid and provide operation stability. Three different wick types are used in PHUMP that vary in size, composition, and thermal-fluidic properties. A high thermal conductivity copper wick is used in the base of the evaporator to effectively conduct heat into the working fluid. This sinter's small pore size inhibits phase change of the working fluid inside the sinter; instead, it occurs in a series of preformed vapor channels. These channels are interconnected by a manifold, which then delivers vapor to the condensers of PHUMP via vapor transport lines.

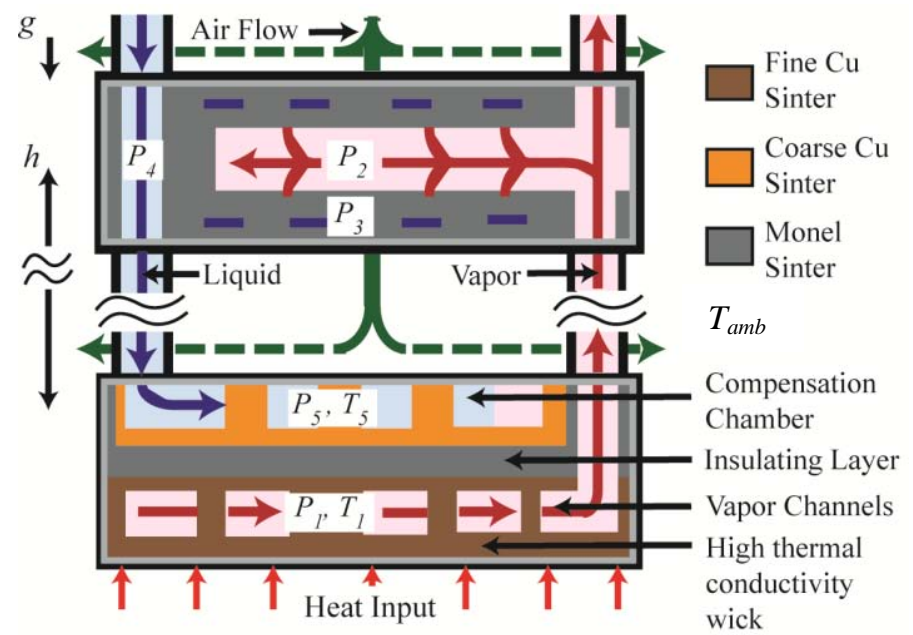

Figure 2: The evaporator and a condenser in PHUMP, including the compensation chamber. The compensation chamber is constructed from a coarse copper sinter, the insulating layer from Monel sinter, and the high thermal conductivity wick uses a fine copper sinter. Note the presence of both liquid and vapor in the compensation chamber.

At the top of the evaporator is the compensation chamber. Made of a coarser copper sinter, it ensures that liquid is distributed within the evaporator, as well as serving an important role in the operational stability of the device.
Between the compensation chamber and the vapor channels of the evaporator lies a layer of Monel sinter known as the insulating layer; it provides thermal separation between the two regions. The evaporator is housed in a machined Monel case with a solid copper base. The thermophysical properties of these three sinter types were characterized by Dominguez [1] and are given in Table 1.

Table 1: Thermophysical properties of sinter types

\begin{tabular}{|l|l|c|}
\hline Sinter & $\begin{array}{l}\text { Thermal Conductivity } \\
{\left[\mathrm{Wm}^{-1} \mathrm{~K}^{-1}\right]}\end{array}$ & Permeability $\left[\mathrm{m}^{2}\right]$ \\
\hline Fine Copper & 65 & $10^{-13}$ \\
\hline Monel & 2.3 & $10^{-12}$ \\
\hline Coarse Copper & 28 & $10^{-12}$ \\
\hline
\end{tabular}

A sintered wick is also employed in the condensers of the device, featuring the same Monel sinter as the evaporator. The geometry of PHUMP results in a gravitational pressure head between the top and bottom most condensers. This sintered wick serves to separate the liquid and vapor phases of the device and prevents flooding of the lower condensers due to the pressure head. Throughout each condenser where the two phases meet, a liquid-vapor interface develops across which a pressure difference is present. This pressure difference is supported by the capillary forces of the interface provided by the Monel wick. The condensers' ability to maintain this pressure difference is critical to the successful operation of the device. To improve the stability of the device, this pressure difference is controlled by the compensation chamber.

The compensation chamber controls the pressure difference across the liquid-vapor interface in the condensers by indirectly controlling the liquid pressure of the device. By maintaining the fluid inside it as a two-phase mixture, the compensation chamber sets the liquid pressure via the temperature-pressure coupling that occurs at saturation. Heat input is required to maintain this saturation state, usually provided by electrical heaters. To reduce power consumption in the device and thus increase its COP, PHUMP instead uses waste heat from the evaporator to heat the compensation chamber. The purpose of this paper is to detail the requirements of the compensation chamber in PHUMP and to outline the processes and techniques used in its design.

\section{DESIGN REQUIREMENTS}

The primary purpose of the compensation chamber in a loop heat pipe is to maintain the stability of the liquid-vapor interfaces within the condensers of the device. In PHUMP, this requirement places specific constraints on the pressure and temperature of the compensation chamber relative to the vapor channels in the base of the evaporator. These constraints govern the design of the compensation chamber and must be fully understood if the device is to operate as desired.

The pressure difference across the liquid-vapor interface in the condensers of PHUMP must always fall between upper and lower bounds set by the two main failure modes of the device. 
First, the vapor pressure must always exceed the liquid pressure on the opposite side of the interface, forming a receding meniscus. If this condition is violated, the liquid in the wick will bulge into the vapor space of the condenser in what is known as an advancing meniscus. This configuration is inherently unstable and eventually leads to flooding of the condenser [1,7]. This reduces the condensation area available to vapor entering the condensers, decreasing the device's performance. This requirement can be expressed in terms of the liquid and vapor pressures condenser, which are then related to the minimum temperature difference between the compensation chamber and vapor channels.

$$
P_{2}>P_{3}
$$

$P_{2}$ is the vapor pressure in the condenser, while $P_{3}$ is the liquid pressure in the condenser wick. This liquid pressure can be related to the liquid pressure in the compensation chamber $\left(P_{5}\right)$ through the viscous losses that occur as the liquid travels through the condenser wick $\left(\Delta P_{3-4}^{v i s c, l}\right)$ and the gravity pressure head $\left(\rho_{l} g h_{\text {min }}\right)$ within the device. As flooding occurs first in the condenser closest to the evaporator (where liquid pressure is highest), we use $h_{\min }$ in the calculation of this limit.

$$
P_{3}=P_{5}-\rho_{l} g h_{\min }+\Delta P_{3-4}^{\text {visc }, l}
$$

Similarly, the vapor pressure in the condenser can be related to that of the vapor channels $\left(P_{1}\right)$ by accounting for the viscous losses that occur as vapor travels through the manifold $\left(\Delta P_{1-2}^{v i s c, v}\right)$ and transport lines.

$$
P_{2}=P_{1}-\Delta P_{1-2}^{v i s c, v}
$$

Relations (2) and (3) can be combined to determine the pressure difference between the compensation chamber and the vapor channels.

$$
P_{1}-P_{5}=\Delta P_{3-4}^{v i s c, l}+\Delta P_{1-2}^{v i s c, v}-\rho_{l} g h_{m i n}
$$

As both the vapor in the evaporator and the compensation chamber are saturated, the pressure difference between the two can be related to their temperature difference using $\left(\frac{d P}{d T}\right)_{\text {sat }}$, the local slope of the saturation curve, or:

$$
P_{1}-P_{5}=\left(\frac{d P}{d T}\right)_{s a t} *\left(T_{1}-T_{5}\right)
$$

Substituting (5) into (4) yields the thermal criteria for the compensation chamber.

$$
\left(T_{1}-T_{5}\right)>\left(\Delta P_{3-4}^{v i s c, l}+\Delta P_{1-2}^{v i s c, v}-\rho_{l} g h_{\min }\right) /\left(\frac{d P}{d T}\right)_{s a t}
$$

This represents a lower bound on the temperature difference between the compensation chamber and the vapor channels; if it is less than this, flooding of the condensers can occur. This necessitates a minimum thermal resistance between the vapor channels and the compensation chamber within the evaporator. Note that we have not included a term to account for the wick's ability to support excess liquid pressure in an advancing meniscus. Due to its unstable nature, once this state is reached flooding is a near certainty and so it is ignored.

The compensation chamber must also prevent the pressure difference across the liquid-vapor interface in the condensers from becoming too large. When this pressure difference exceeds what can be supported by the Monel wick in the condensers, vapor will penetrate into the liquid side of the device where it travels to the evaporator. This can lead to dryout of the evaporator, a catastrophic failure mode. The maximum pressure difference that a condenser can maintain, defined here as $P_{c a p}$, is determined experimentally using a methodology described by Hanks [2]. Typical values for $P_{c a p}$ in this environment are $8.0 \mathrm{kPa}$.

For any condenser in the device, the pressure difference across the liquid-vapor interface must be less than $P_{c a p}$. As vapor penetration will first occur in the condenser furthest from the evaporator (where liquid pressure is the lowest), $h_{\max }$, the distance between the compensation chamber and the top condenser, is used in the calculation of this limit.

$$
P_{\text {cap }}>P_{2}-P_{3}
$$

Using relations (2), (3), and (5), this requirement can be rearranged to relate the pressure difference across the liquidvapor interface in the condenser to the temperature difference between the compensation chamber and the vapor channels.

$$
\begin{aligned}
P_{c a p}+\Delta P_{1-2}^{v i s c, v}+ & \Delta P_{3-4}^{v i s c, l}-\rho_{l} g h_{\max } \\
& >\left(\frac{d P}{d T}\right)_{\text {sat }} *\left(T_{1}-T_{5}\right)
\end{aligned}
$$

Relation (8) places an upper bound on the temperature difference between the compensation chamber and the vapor channels and provides the maximum possible thermal resistance between the two. Relations (6) and (8) dictate the design of the evaporator, as the thermal resistances of various components need to be tailored to meet these requirements.

Table 2 below includes typical values for many of the parameters used in the above equations for operation at a fan speed of 6000 RPM and a heat load of $1125 \mathrm{~W}$.

Table 2: Values of parameters used in calculation of operating limits

\begin{tabular}{|c|c|}
\hline Quantity & Value \\
\hline$P_{1}$ & $34.6 \mathrm{kPa}$ \\
\hline$\Delta P_{3-4}^{\text {visc,l }}$ & $1.83 \mathrm{kPa}$ \\
\hline$\Delta P_{1-2}^{\text {visc, }}$ & $2.25 \mathrm{kPa}$ \\
\hline$\rho_{l} g h_{\max }$ & $1.0 \mathrm{kPa}$ \\
\hline$\rho_{l} g h_{\min }$ & $0.2 \mathrm{kPa}$ \\
\hline$P_{\text {cap }}$ & $8.0 \mathrm{kPa}$ \\
\hline$T_{\text {ambient }}$ & $22.5^{\circ} \mathrm{C}$ \\
\hline$T_{1}$ & $72.5^{\circ} \mathrm{C}$ \\
\hline$\left(\frac{d P}{d T}\right)_{\text {sat }}$ & $1.47 \frac{\mathrm{kPa}}{{ }^{\circ} \mathrm{C}}$ \\
\hline
\end{tabular}

The compensation chamber serves a number of other important purposes within PHUMP related to the operation of the device [3,4]. In particular, it must also provide a space for the thermal expansion of the working fluid across a range of operating conditions. When water is used as the working fluid over an operational range of $50{ }^{\circ} \mathrm{C}$, the change in volume of the liquid side is nearly $3 \%$, and the compensation chamber must be large enough to provide space for this expansion. 


\section{COMPUTATIONAL SIMULATION \& METHODOLOGY}

Numerous different compensation chamber designs were considered for use in the final PHUMP prototype. These designs featured a wide range of materials and geometries. Computational simulations were used to efficiently predict the effects of changes to the existing evaporator geometry and arrive at a design that met the requirements described above. A finite element analysis software package, COMSOL

Multiphysics v3.5a, was used to perform these simulations.

A model of the PHUMP evaporator was developed in COMSOL. All materials were assigned appropriate thermal fluidic properties, either from established literature, or in the case of the sintered wicks, experimentally determined by Dominguez [1]. These properties are presented in Table 1 above. Boundary conditions were applied to relevant surfaces on both the exterior and interior of the evaporator. This includes the base (uniform heat flux), sides (convective heat transfer due to natural convection) and top of the evaporator (convective heat transfer due to forced convection from impeller). Boundary conditions were also applied to the fluid connections, replicating the effects of subcooled liquid returning from the condensers and vapor exiting the evaporator.

The convective heat transfer on the top surface of the evaporator has a significant effect on the temperature distribution inside the compensation chamber. Previous work has indicated that the surface temperatures of both the evaporator and the condenser directly above it are nearly uniform [6]; however, as air flows outward over the evaporator surface, the air increases in temperature. This was replicated computationally by applying a uniform heat transfer coefficient (experimentally determined by Staats [5]) to the evaporator surface and a radial temperature distribution to the air that flows over it.

The appropriate physics were applied using a combination of two modules in COMSOL: Darcy's Law to simulate fluid flow in the porous media, and Convection \& Conduction for the heat transfer. Different operating points were simulated for each design by changing the relevant parameters: the heat input into the base, the vapor temperature, and the fan speed and thus the convective heat transfer coefficient on the surface of the evaporator. COMSOL's GMRES (Generalized Minimum RESidual) stationary linear system solver was used in all simulations.

To stabilize the liquid-vapor interfaces in the condensers, the temperature difference between the compensation chamber and the vapor channels must fall within the bounds established by relations (6) and (8). To achieve the necessary thermal resistances, careful design of the evaporator is required. While numerous compensation chamber designs and geometries were explored, cost and time constraints dictated a simple design based on that used in previous prototypes.

The design solution used in the final prototype features two key changes to previous designs to achieve the required performance. First, the thermal resistance of the insulating layer that separates the compensation chamber and the vapor channels of the evaporator is reduced by removing Monel sinter from this layer and replacing it with more conductive copper sinter. Additionally, the convective heat transfer on the evaporator surface is modified to produce the desired thermal resistance by using a different impeller design here.

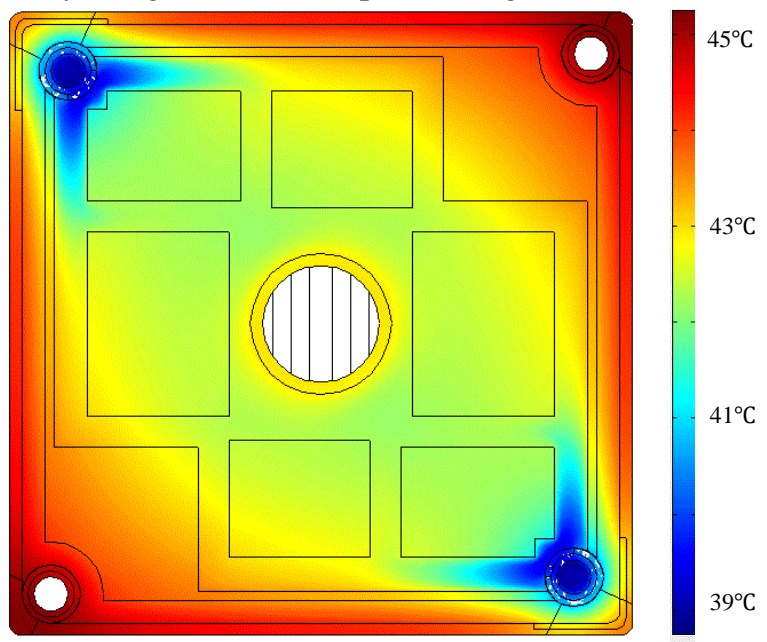

Figure 3: Model of compensation chamber from COMSOL simulations. This is a post processed image from a completed simulation, showing the temperature distribution in the compensation chamber for a heat input of $500 \mathrm{~W}$.

A multi-step process was used to evaluate the performance of different evaporator designs. First, thermal images are inspected to determine the hottest point within the compensation chamber; one such image is shown in Fig. 3. Vapor forms here first, and the temperature of this point represents the saturation temperature of the compensation chamber. The associated pressure is then determined using the saturation curve for the working fluid. Using this information and relations (2) and (3), the pressure difference across the liquid-vapor interface is calculated. This procedure was repeated for various designs across a range of operating conditions, producing a set of data relating liquid-vapor pressure difference in the condensers and operating point. This data can be represented graphically to compare different designs, such as in Figs. 4 and 5. The uncertainty introduced through the thermal image inspection technique was $+/-0.25 \mathrm{~K}$.

\section{COMSOL RESULTS AND DISCUSSION}

By varying the thermal resistance between the compensation chamber and the vapor channels and between the compensation chamber and the ambient air above it, the temperature of the compensation chamber can be tailored to fall within the constraints set by the geometry and operating conditions of PHUMP.

Heat transfer between the compensation chamber and the vapor channels occurs by conduction through the sinter layers of the evaporator. The dominant thermal resistance is provided by the $4 \mathrm{~mm}$ thick insulating layer of Monel sinter used in previous prototypes. Although this initial design was effective at low heat loads $(<500 \mathrm{~W})$, simulations indicated that at higher 
heat loads and operating temperatures the temperature difference between the compensation chamber and the vapor in the evaporator would have exceeded that allowed by relation (8), placing excessive stress on the liquid-vapor interface in the condensers and risking vapor burst through. To alleviate this stress, the thermal resistance of this insulating layer was reduced by thinning the layer of Monel sinter and replacing it with higher conductivity copper sinter from the compensation chamber. Conversely, if the thermal resistance of the insulating layer is reduced too much, relation (2) may be violated and condenser flooding can occur. Various compositions of copper and Monel sinter were considered for this intermediate layer; a number of the designs considered are shown in Fig. 4 below. Note that at high heat loads the pressure difference across the liquid-vapor interface in the original design exceeds the $8 \mathrm{kPA}$ capillary pressure limit of the condensers.

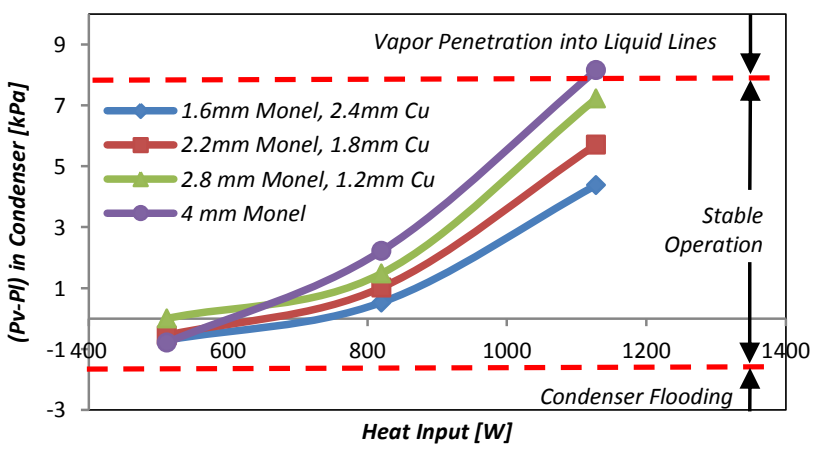

Figure 4: Pressure difference across liquid-vapor meniscus in condensers as a function of heat load for a variety of insulating layer compositions. The dashed lines indicate the pressure limits for both condenser flooding and vapor penetration.

At high fan speeds and heat loads, the effect of convective heat transfer becomes greater, and the temperature difference between the compensation chamber and the vapor channels increases. This increases the pressure difference across the liquid-vapor interfaces in the condensers and thus also the risk of vapor penetration. To avoid this failure mode, the convective heat transfer from the compensation chamber was reduced by using a different impeller design directly above the evaporator. For equivalent rotational speeds, this impeller features a convective heat transfer coefficient that is approximately $25 \%$ less than the impellers used in the rest of the device. This increases the temperature of the compensation chamber relative to the evaporator vapor channels and reduces the risk of vapor penetration into the liquid side of the device.

The design selected for use in the final PHUMP prototype features an insulating layer composed of $2.2 \mathrm{~mm}$ of Monel sinter and $1.8 \mathrm{~mm}$ of coarse copper sinter along with the aforementioned impeller design. The expected pressure difference across the liquid-vapor interface in the condenser is shown for a variety of heat loads and fan speeds in Fig. 5. The final design features a total open volume of $6.6 \mathrm{~mL}$ to allow for thermal expansion of the working fluid.

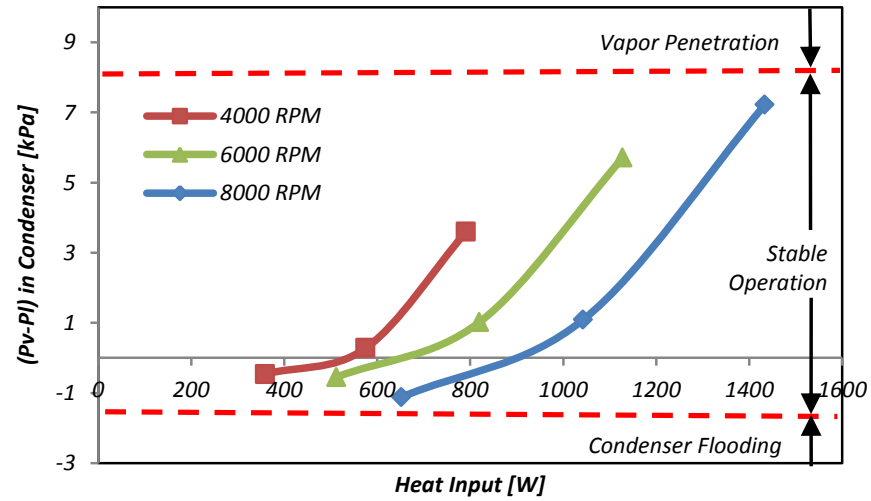

Figure 5: Pressure difference across liquid-vapor meniscus in condensers at various heat loads and fan speeds. The dashed lines indicate the pressure limits for both condenser flooding and vapor penetration.

\section{CONCLUSIONS}

We have designed a compensation chamber for use in a multiple condenser loop heat pipe that achieves the requirements necessary for successful operation over a wide range of conditions. Most importantly, this device maintains the stability of the liquid-vapor interfaces in the condensers to mitigate the risk of condenser flooding and evaporator dry out. Computational simulations performed with COMSOL Multiphysics, along with data from past experiments, were used to predict the effects of design changes. Currently, the compensation chamber is being incorporated into the final PHUMP prototype as part of the evaporator. Future works will report the performance of this device as well as the manufacturing techniques used to construct it.

\section{NOMENCLATURE}

$P_{1} \quad$ Vapor channel pressure, $\mathrm{kPa}$

$P_{2} \quad$ Condenser vapor pressure, $\mathrm{kPa}$

$P_{3} \quad$ Condenser wick liquid pressure, $\mathrm{kPa}$

$P_{4} \quad$ Condenser liquid pressure, $\mathrm{kPa}$

$P_{5} \quad$ Compensation chamber pressure, $\mathrm{kPa}$

$T_{1} \quad$ Vapor channel temperature, ${ }^{\circ} \mathrm{C}$

$T_{5} \quad$ Compensation chamber temperature, ${ }^{\circ} \mathrm{C}$

$\Delta P_{1-2}^{\text {visc,v }}$ Viscous pressure drop in vapor channels, $\mathrm{kPa}$

$\Delta P_{3-4}^{\text {visc,l }}$ Viscous pressure drop in condenser wick, $\mathrm{kPa}$

$\rho_{l} g h_{\text {max }}$ Maximum gravity pressure head, $\mathrm{kPa}$

$\rho_{l} g h_{\min } \quad$ Minimum gravity pressure head, $\mathrm{kPa}$

$P_{\text {cap }} \quad$ Maximum liquid-vapor pressure difference that can be sustained by condenser wick, $\mathrm{kPa}$

$T_{\text {ambient }}$ Ambient temperature, ${ }^{\circ} \mathrm{C}$

$\left(\frac{d P}{d T}\right)_{\text {sat }} \quad$ Saturation curve slope, $\frac{\mathrm{kPa}}{{ }^{\circ} \mathrm{C}}$

$h \quad$ Condenser height relative to compensation chamber, $\mathrm{m}$

g Gravitational constant, $\mathrm{m}^{2} / \mathrm{s}$ 


\section{ACKNOWLEDGMENTS}

This work is supported by the Defense Advanced Research Projects Agency (DARPA) Microsystems Technology Office (MTO) Microtechnologies for Air-Cooled Exchangers (MACE) program, Grant Number W31P4Q-09-1-0007, with Dr. Tom Kenny and Dr. Avi Bar-Cohen as program managers.

\section{REFERENCES}

1. Dominguez-Espinosa, F.A., 2011. Effect of fabrication parameters on thermophysical properties of sintered wicks. Master's thesis, Massachusetts Institute of Technology.

2. Hanks, D.F., 2012. Design, Fabrication, and Characterization of a Multi-Condenser Loop Heat Pipe. Master's Thesis, Massachusetts Institute of Technology
3. Faghri, A., 1995. Heat Pipe Science and Technology. Taylor \& Francis Group.

4. Reay, D., and Kew, P., 2006. Heat Pipes: Theory, Design, and Applications, $2^{\text {nd }}$ ed. Butterworth-Heinemann.

5. Staats, Jr., W.L, 2012. Active Heat Transfer Enhancement in Integrated Fan Heat Sinks. Ph.D. thesis, Massachusetts Institute of Technology.

6. Ku, J., 1999. Operating Characteristics of Loop Heat Pipes. SAE Technical Paper 1999-01-2007.

7. McCarthy, Matthew et al., 2010. Design and Analysis of High-performance Air-cooled Heat Exchanger with an Integrated Capillary-pumped Loop Heat Pipe. Proceedings of the 12th IEEE Intersociety Conference on Thermal and Thermomechanical Phenomena in Electronic Systems, 18. 